\title{
Cuerpos difusos. Una lectura QUEER DE TRES NOVELAS DE CIENCIA FICCIÓN COLOMBIANA*
}

\author{
Fuzzy Bodies. A Queer Reading of Three \\ Colombian Science Fiction Novels
}

Juan Alberto Conde Aldana ${ }^{1}$

\footnotetext{
* Cómo citar este artículo: Conde Aldana, J. A. (2022). Cuerpos difusos. Una lectura queer de tres novelas de ciencia ficción colombiana. Estudios de Literatura Colombiana 50, pp. 145163. DOI: https://doi.org/10.17533/udea. elc.n50a08

1 https://orcid.org/0000-0002-3052-6869 juan.conde@utadeo.edu.co

Universidad de Bogotá Jorge Tadeo Lozano, Colombia
}

Editores: Andrés Vergara Aguirre, Christian Benavides Martínez

Recibido: 15.08 .2021

Aprobado: 29.10.2021

Publicado: 17.01 .2022

Copyright: @2022 Estudios de Literatura Colombiana. Este es un artículo de acceso abierto distribuido bajo los términos de la Licencia Creative Commons Atribución - No comercial - Compartir igual 4.0 Internacional
Resumen: En este artículo se analizan tres novelas colombianas de ciencia ficción recientes en las que se explora una temática común: la presentación de sexualidades no binarias, que se materializa a través de la representación del cuerpo y sus transformaciones. Mi objetivo es mostrar cómo las estrategias expresivas de la ciencia ficción permiten abordar esta temática de difícil aproximación en la literatura realista, expandiendo las reflexiones sobre el cuerpo y la sexualidad en el mundo contemporáneo. El marco teórico para este análisis proviene de la narratología, en dos de sus desarrollos contemporáneos: la narratología queer y la narratología corpórea.

Palabras clave: Ciencia ficción colombiana; teoría queer; narratología postclásica; cuerpo; narratología corpórea.

Abstract: In this article, three recently published Colombian science fiction novels are analyzed, in which a common theme is explored: the presentation of non-binary sexualities, materialized through the representation of the body and its transformations. My objective is to show how the expressive strategies of science fiction allow to address this issue in ways that are difficult to find in realistic literature, expanding the reflections on the body and the sexuality in our world. The theoretical framework for this analysis comes from narratology, in two of its contemporary developments: queer narratology and corporeal narratology.

Keywords: Colombian Science Fiction; Queer Theory; Postclassical Narratology; body; Corporeal Narratology. 


\section{Introducción: teoría queer y narratología}

Después de su aparición en las últimas décadas del siglo xx, la teoría queer se ha consolidado como un campo académico de gran impacto en los estudios estéticos y literarios, paralelamente a su desarrollo como una forma de activismo intelectual concentrado en la esfera política y social más amplia. Derivada de los estudios gay y lésbicos, la teoría queer se ha extendido a diversas formas de cuestionamiento de las relaciones rígidas entre sexo, género y deseo, expandiéndose además a la comprensión y defensa de todas las prácticas e identidades que se construyen por fuera del imperativo heteronormativo de la cultura dominante.

Los estudios narrativos no se han visto privados de esta influencia. En particular, tras su etapa fundacional en el contexto del estructuralismo en la obra de autores como Tzvetan Todorov y Gérard Genette, colindando con la semiótica narrativa de Roland Barthes o Algirdas J. Greimas, la narratología recibió la influencia primero del feminismo y los estudios de género, dando un giro más consciente hacia la problematización de la sexualidad en la obra de autoras como Julia Kristeva o Teresa de Lauretis, y luego empezó a introducir abiertamente la perspectiva queer en sus indagaciones sobre las formas narrativas.

Este giro se materializó en el contexto de lo que David Herman ha denominado la narratología postclásica, que en su primera fase supuso un desplazamiento del formalismo estructuralista hacia aproximaciones pragmáticas o cognitivas y que luego experimentó una segunda etapa caracterizada por la diversificación de sus métodos y objetos de análisis:

[...] postclassical narratologies [...] seem to move toward a grand contextual, historical, pragmatic and reader-oriented effort. Such integration and synthesis allows researchers to recontextualize the classical paradigm and to enrich narrative theory with ideas developed after its structuralist phase. While classical narratology was a relatively unified discipline or field, postclassical narratologies are part of a large transdisciplinary project that consists of various heterogeneous approaches (Albert y Fludernik, 2010, p. ๑).

Es en este contexto que surgen las narratologías feministas y queer que nutren este artículo. En su obra Narrative Theory Unbound. Queer and Feminist Interventions, Robyn Warhol y Susan S. Lanser (2015), pioneras en la integración de estos dos enfoques, ofrecen un completo recorrido por las obras y autoras representativas de estas líneas narratológicas. En términos de estas autoras, 
For feminist and queer narrative theory, gender matters, in the sense that gender makes a difference in the production and reception of texts, and also in the sense that the gendering of writing and reading has its basis in - and an impact upon - lived experience in the material world. Today feminists generally join queer theorists in understanding gender difference to be a cultural construction, not a biological given, and in recognizing that both gender and sexuality exist along a variegated spectrum that individual subjects experience in shifting ways across a lifetime (Warhol y Lanser, 2015, p. 7).

Así, al momento de describir las formas narrativas de las obras que entran en su corpus de estudio, las narratologías feministas y queer comparten el interés por no excluir las constricciones contextuales, históricas, políticas y culturales que determinan dichas formas y su manera de interpelar, o incluso determinar, las identidades y los cuerpos.

\section{Cuerpo y narratología}

Este giro contextualista o pragmático de las narratologías postclásicas ha conducido a diversas consideraciones en torno al carácter corporeizado de las experiencias narrativas tanto desde su creación como en su recepción. No obstante, Daniel Punday señalaba, a principios del siglo xxi, que mientras la filosofía, la lingüística o los estudios literarios y culturales reconocían cada vez con más fuerza el papel del cuerpo en el conocimiento y la construcción del sentido, la narratología parecía mantenerse al margen de esta tendencia. Punday subrayaba la narratología feminista como una excepción a esta omisión, que constituía un antecedente (aunque perfectible) de su propuesta de una narratología corpórea (corporeal narratology) (Punday, 2003, pp. 4-7).

Los desarrollos posteriores de las narratologías feminista y queer superan algunas de las críticas formuladas por Punday, compartiendo las particularidades que este enfoque ofrece a los estudios narrativos. Evocando las ideas de Gerald Prince, Punday identifica dos tipos de cuestiones que se plantea la narratología: las cuestiones del "cómo" (las formas narrativas) y las del "qué" (los temas o contenidos narrativos), para señalar que los estudios narrativos se han enfocado en las primeras, en detrimento de las segundas (p. 3). De acuerdo con Punday, esta es una de las razones principales que condujeron a la omisión del cuerpo en las reflexiones sobre la narrativa, pues este tiene que ver, en su dimensión más evidente, con las cuestiones del "qué" (los cuerpos representados). De hecho, Punday subraya que cuando es tenido en cuenta por la narratología clásica, el cuerpo aparece como un elemento más dentro de los objetos que pueblan un universo diegético (pp. 3-4). 
No obstante, el cuerpo también puede ser aproximado desde cuestiones relativas al "cómo", esto es, las formas narrativas, y en particular a lo que la narratología y la semiótica clásicas denominaban la instancia de la enunciación, o la mediación narrativa. La combinación de estas dos perspectivas constituye la propuesta de una narratología corpórea (Punday, 2003, p. 9).

En este artículo se asume una perspectiva similar a la planteada por Punday, haciendo más énfasis en la dimensión de los cuerpos representados, aunque también se formulan algunas ideas relativas a la mediación narrativa de los cuerpos. El género literario escogido para esta aproximación es el de la ciencia ficción en el contexto colombiano.

\section{La aproximación queer a la ciencia ficción}

Aunque no es abundante la literatura académica que aborda la ciencia ficción desde las perspectivas feminista y queer, las autoras y obras que inauguran este campo han subrayado la capacidad de este género para cuestionar las formas de comprensión tradicionales del cuerpo y la sexualidad. Una de estas autoras es Wendy Gay Pearson, quien ha establecido una interesante conexión entre la definición de la ciencia ficción como un género basado en el "extrañamiento cognoscitivo", según la ya clásica aproximación de Darko Suvin (1984), y las propuestas más radicales de la teoría queer. De acuerdo con Suvin, la ciencia ficción es un género del extrañamiento, en tanto toma distancia frente a la tradición realista, "naturalista o empírica", al introducir elementos que transgreden la concepción de lo real de una época o sociedad; pero, a diferencia de otros géneros fantásticos, lo hace a través de la extrapolación de elementos "cognoscitivos", esto es, que pueden ser considerados como plausibles por la episteme dominante de esa época o sociedad (Suvin, 1984, pp. 25-33). Como señalan Pearson, Hollinger y Gordon (2008), la teoría queer se asocia con los intentos de la ciencia ficción por "defamiliarize and denaturalize taken-for-granted constructions of what it means to be, and to live, as a human" (p. 6).

En términos metodológicos, esto se traduce en dos formas de aproximación queer a la ciencia ficción: la práctica de una 'lectura queer' de obras del género y el reconocimiento de obras queer en su propio planteamiento. En el análisis que aquí se propone de las obras de ciencia ficción colombiana seleccionadas se seguirá esta segunda línea, identificándolas con la tendencia queer de la ciencia ficción contemporánea. 


\section{La ciencia ficción colombiana}

Si bien constituye un género todavía periférico, en Colombia la ciencia ficción tiene una presencia cada vez más visible en el panorama literario local. Si durante el siglo $\mathrm{xx}$ este género tuvo una aparición intermitente u ocasional, como han señalado teóricos del género en este país como Rodrigo Bastidas y Campo Ricardo Burgos López —en "La ciencia ficción colombiana entre milenios" (2012) y "La narrativa de ciencia ficción en Colombia” (2000), respectivamente-, en el siglo xxi su presencia no solo se ha visto aumentada, sino diversificada en términos de temas y abordajes. Esto se puede evidenciar de varias maneras: en primer lugar, en la recuperación, por parte de la editorial Laguna Libros, de tres obras olvidadas de la primera mitad del siglo xx: Una triste aventura de catorce sabios (1928), de José Félix Fuenmayor, Barranquilla 2132 (1932), de José Antonio Osorio Lizarazo y Viajes interplanetarios en zepelines que tendrán lugar el año 2009 (1936), de Manuel Francisco Sliger. El redescubrimiento de estas obras abre la posibilidad de concebir una tradición más extensa de lo que se pensaba para el género en Colombia. En segundo lugar, en el hecho de que autores y autoras mainstream, como Juan Cárdenas, Álvaro Robledo o Andrea Salgado, se han aproximado al género en tiempos recientes; en tercer lugar, en la aparición de editoriales colombianas especializadas en ciencia ficción, como Ediciones Vestigio o Mirabilia Libros; y, en cuarto lugar, en la apertura de líneas editoriales dedicadas a la fantasía y la ciencia ficción en casas editoriales de envergadura internacional, como el Grupo Planeta o Penguin Random House. Prueba de ello es la edición, a cargo de Rodrigo Bastidas, de la Antología de ciencia ficción colombiana (2017) en dos volúmenes que recoge los nuevos nombres y tendencias de la ciencia ficción en el país, además de la publicación de obras como las que se analizarán a continuación.

Las tres novelas seleccionadas, dos de ellas escritas por mujeres, tienen varios puntos en común, además de la presencia de temáticas queer en sus universos narrativos, o de plantear abiertamente reflexiones sobre el cuerpo y la sexualidad: las tres se inscriben dentro de lo que la tradición del género denomina la ciencia ficción blanda, en la medida en que, aunque todas ellas incluyen discursos científicos en la sustentación de sus procesos de extrañamiento, ninguna se detiene particularmente en la descripción detallada o minuciosa de dichos discursos. Así mismo, las tres se aproximan a tendencias contemporáneas de la fantasía y la ciencia ficción como el cyberpunk, el new weird o incluso el bizarro. Finalmente, hay una cercanía generacional entre sus 
autores que se refleja en sus sensibilidades e intereses hacia temas como los que se contemplan a continuación.

\section{La lesbiana, el oso y el ponqué: experiencia virtual y experiencia orgánica}

La novela de Andrea Salgado cuenta la historia de Lucas Valencia, una mujer que trabaja para un juego denominado La calle, en el que expone su vida en tiempo real ante los usuarios del juego, que viven todas las experiencias de ella a través de un sistema de realidad vicarial: el Simulador de vida orgánica (sDvo), un dispositivo que se instaló “en el sistema nervioso al inicio de los tiempos digitales"(Salgado, 2017, p. 13). Estas experiencias son distribuidas y mercantilizadas como contenidos mediáticos que los usuarios deben comprar y pagar a través de actualizaciones, promociones y paquetes especiales. La vida de Lucas se convierte en un producto especialmente apetecido, pues ofrece experiencias sexuales y emocionales frecuentes y diversas, mientras que las existencias de los usuarios en su vida real son completamente estandarizadas: todos y todas consumen los mismos productos sintéticos, siguen las mismas rutinas, tienen las mismas familias modélicas, repiten las mismas fórmulas.

La novela plantea la cuestión de la relación cuerpo-género en dos niveles: en el relato marco, por un lado, que constituye este trasfondo de ciencia ficción en el que las experiencias, sensaciones y deseos de la protagonista son vividos artificialmente por los usuarios de La calle, convirtiendo a Lucas en una proveedora de "vida orgánica"; y por otro lado, en el relato enmarcado, que constituye la vida de Lucas Valencia tal y como es ofrecida a los usuarios: una mujer que, en medio de su crisis de la mediana edad (tiene 36 años), se involucra en una relación heterosexual, siéndole infiel a su pareja, Clara, con un hombre gordo y peludo como un oso. Este nivel narrativo constituye una novela de formación, de descubrimiento de la identidad sexual de la protagonista, atravesada por un conjunto de reflexiones sobre la corporeidad. Esta historia está construida según las claves de la literatura realista: nos cuenta los encuentros y desencuentros de la protagonista con sus diferentes parejas desde su adolescencia: sus primeras experiencias sexuales y emocionales con hombres y su paulatino descubrimiento de que prefiere a las mujeres. En este nivel, Lucas devela una idea nítida de su cuerpo que alterna dos imaginarios contemporáneos de la corporeidad: el régimen del ejercicio, la salud y la esbeltez (el “cuidado del cuerpo"), y el régimen hedonista del placer, la experimentación y la transgresión; dos regímenes que se alternan en su vida 
y que finalmente colisionan cuando conoce a Jerónimo, el Oso. Este pone en crisis el primer régimen, que se consolidó cuando ella era una niña de 10 años:

Durante toda su vida Lucas había sido una gordofóbica y estaba convencida de que todos los gordos eran unos zánganos que se merecían su destino. El asunto había comenzado después de la graduación de primaria cuando su papá la premió con un viaje a Walt Disney y ella conoció no solo a Mickey y sus amigos, sino a la obesidad norteamericana [...]. Víctimas para el sacrificio de la prosperidad. Asco. Miedo. Una sensación de lástima que de tan intensa se convertía en desprecio. Un sentirse mal por sentir lástima. Desgraciados gordos que la hacían odiarse a ella misma por sentirse mal por ellos. El descubrimiento de la compasión como mecanismo de discriminación. Ella, la pequeña Lucas, la discriminadora de gordos, aterrada de que algún día, castigo divino, se volviera tan gorda como ellos, durante todas las vacaciones se negó a comer comida rápida. Tenía to años y ese verano fue la primera vez que declaró que estaba dieta (Salgado, 2017, p. 42).

Este temprano ascetismo acompaña a Lucas durante buena parte de su vida, pero se fractura con su encuentro con el Oso: con él se entrega a todas las formas de goce tanto en las prácticas eróticas como en las gastronómicas. Paradójicamente, lo conoce en el parque mientras hace su rigurosa rutina de ejercicios. En su primer encuentro, el imaginario de la obesidad se transmuta a través de su fascinación por Jerónimo, y en particular por su olor. Además de hacerla transitar hacia el régimen del hedonismo, Jerónimo lleva a Lucas a cuestionar su identidad. No tanto por involucrarla en una relación heterosexual en plena edad madura, después de décadas sin acostarse con un hombre, lo cual no supone para ella un conflicto mayor, sino porque, al estar engañando a su pareja, Clara, siente que está cayendo en las formas más nocivas de la masculinidad colombiana:

[...] a veces piensa que todo es culpa del sistema social monógamo y heterosexual en el que nacieron, en el que la vida de Clara, Jerónimo y ella se desarrolla. Lo mejor sería amarlos a los dos, claro. El uno, la sexualidad. La otra, la conexión espiritual. ¿Por qué justo ahora ama dividida? Como un macho colombiano. Como un macho colombiano. A veces le da pereza complicarse tanto la vida; un hombre y una mujer exigen mucho tiempo y esfuerzo. [...] Si ya es difícil para ella ser lesbiana en este país homofóbico, ¿̇qué decir de ser lesbiana y marica al mismo tiempo? Esa sí que sería una lucha (Salgado, 2017, p. 82).

Este pasaje ejemplifica además las constantes reflexiones que Salgado introduce en su novela sobre las complejas relaciones entre sexo, género y deseo, para recuperar la red de conceptos propuesta por Judith Butler (2007):

Si la "identidad" es un efecto de las prácticas discursivas, ċhasta qué punto la identidad de género, vista como una relación entre sexo, género, práctica sexual y deseo, es el efecto de una práctica reguladora que puede definirse como heterosexualidad obligatoria? ¿Nos devolvería esa explicación a otro marco totalizador en el que la heterosexualidad obligatoria simplemente ocupa el lugar del falogocentrismo como la causa monolítica de la opresión de género? (p. 73). 
En el caso de Lucas, esta relación entre sexo, género y deseo involucra otro conjunto de cruces y divergencias: el hecho de que su deseo se asocie con un hombre, después de años de estar vinculado con las mujeres, y que su larga relación con Clara esté relacionada con la "espiritualidad" podría leerse como un simple retorno a la heteronormatividad parcialmente neutralizada por el carácter no normativizado del cuerpo de Jerónimo. No obstante, este Oso no deja de ser una presencia masculina, como lo enfatizan las intervenciones fantasmales de la madre de Lucas (de las que se hablará más adelante), quien la invita a abandonar a Clara y oficializar su relación "con un hombre”. En este aspecto, la novela de Salgado constituye también una discusión sobre las relaciones de sujeción entre la heterosexualidad, la homosexualidad y la heteronormatividad, cuestionadas por la teoría queer, la cual "has been principally concerned with the hierarchical nature of the heterosexual/homosexual binary, but this binary is understood as not so much expressive as constitutive of heterosexual power" (Carroll, 2012, p. 6).

Este cuestionamiento se desarrolla en el relato de la vida de Lucas y su triángulo amoroso, que parece resolverse cuando ella opta por Clara y se desconecta de Jerónimo. No obstante, en un momento de debilidad trata de reencontrarse con él sin tener muy claro si lo que quiere es reiniciar su relación extramarital, en una escena que involucra el ponqué del que se habla en el título de la novela, y que es una metonimia de los placeres gastronómicos compartidos con el Oso.

El nivel "realista", no obstante, está enlazado de manera inteligente con el relato marco en clave de ciencia ficción. De hecho, en este otro nivel se incluyen consideraciones metanarrativas que desdibujan el orden de los géneros:

Millones de seguidores pagan a diario por conectarse a tu experiencia y vivir virtualmente tu vida. [...] Tú, mejor que nadie, sabes que las estadísticas muestran que en los últimos meses la opción fiction es una de las menos usadas. Los habitantes te quieren a ti, solo a ti, a nadie más que a ti. Mira, querida, te voy a ser sincera: deja de insistir con todos esos subgéneros obsoletos; el terror, los thrillers, la ciencia ficción y sus hijas; las distopías, utopías y ucronías y toda esa mierda fantasiosa. [...] Dime, Lucas: chace cuánto crees que murió la ficción y tú sigues insistiendo? (Salgado, 2017, pp. 16-17).

La cita anterior también propone una inversión de la tradicional relación "vida real de los usuarios/universo fantástico en los videojuegos”. Así mismo, el carácter hedonista de la vida de Lucas está articulado con el hecho de que los contenidos de su experiencia son los que la hacen atractiva para sus "consumidores": 
“Con Lucas y el Oso es posible disfrutar una variedad de alimentos hipercalóricos, altos en azúcar y grasas saturadas y, sobre todo, representativos de la gastronomía mundial sin subir ni un gramo". "Reírse mientras se copula, no distinguir entre la lujuria y la risa: una experiencia orgánica a la que nunca había accedido". "Que se pueda sentir deseo por un adefesio como ese, por un gordo calvo y peludo que violenta todas las medidas de una sociedad sana y civilizada...” [...]. "Accede a Lucas, hazme caso. Ella copulará por ti y así copularás sin copular. Copula como una infecta a través de Lucas. Que sea Lucas quien se ponga en riesgo de contaminación, mientras tú te mantienes en completa asepsia y además libre, hija mía, libre de los dolores del amor carnal”, añade Control Master (p. 38).

En esta misma línea, la enunciación narrativa es traducida a términos técnicos y comerciales desde el principio de la novela: en un pequeño prólogo, que toma la forma de un mensaje informativo para los usuarios del sDvo, se describen tres modalidades de "consumo narrativo": el primero ofrece la posibilidad de elegir entre FICTION y NON-Fiction; el segundo, permite hacer un MASH up, que parece ser la modalidad que le ofrece una participación más "creativa" al espectador; finalmente, se ofrecen dos opciones de acceso a la vida del proveedor (en este caso, Lucas): la opción MÁQUiNA DEL TIEMPo, a través de la cual se puede acceder a momentos pasados de su vida "sin la terrible cadena de la linealidad vivencial", y el modo sherezada, que permite un acceso "en directo" a "la multiplicidad de la experiencia sin barreras espaciotemporales o argumentales". La introducción funciona, así, como un dispositivo narratológico que ofrece al lector las claves interpretativas de la propia forma narrativa de la novela, la cual, efectivamente, está narrada según un conjunto de prolepsis que dan acceso a la historia pasada de Lucas, redactada además en pretérito indefinido, desde su infancia hasta su adultez (modo MÁquina DEL TIEMPo) y del relato primero que se narra en tiempo presente (modo SHEREZADA).

No obstante, este prólogo simuladamente metanarrativo supone, además, otra instancia de enunciación relacionada con un personaje virtual que interactúa tanto con los usuarios de La calle como con Lucas, la proveedora de experiencias: el Control Master, que se expresa en segunda persona, como puede verse en los pasajes arriba citados. Pero el aspecto más interesante de la arquitectura narratológica de esta novela tiene que ver con la relación que establece con su narratario, al ubicar al lector en la posición de los usuarios de La calle: como estos, los lectores devenimos voyeurs, viviendo de manera indirecta las experiencias de Lucas, haciendo del libro de Andrea Salgado nuestro "proveedor de vida orgánica". 
Esta temática emparenta la novela de Salgado con el subgénero del ciberpunk, en particular con lo que se ha identificado como su segunda generación, la cual tiene una presencia más fuerte de escritoras y hay una determinante influencia de diversos feminismos. Como ha señalado Carlen Lavigne (2013), el ciberpunk feminista retoma temas que se encontraban ya en la primera generación, como "cyborgs/artificial intelligence and the 'human' condition, embodiment and virtual reality, and capitalist globalization" (p. 31), pero los explora de manera diferente: "with more emphasis on the importance of the body in identity and relationships, and the importance of community support in the face of alienating multinational capitalism" (p. 32).

Esto se traduce, en la novela de Salgado, en el MAsh up, en el que el relato realista se mezcla con el modo fiction, cuando a Lucas se le aparece, en la forma de un fantasma concejero, su madre fallecida años atrás, que juzga su vida o le indica directrices para enmendarla. Esta aparición tiene sutiles resonancias con el realismo mágico latinoamericano, citado de manera paródica al convertir esta presencia en un fantasma digital inducido por el propio dispositivo sDvo. No obstante, hay una suerte de sororidad en esta relación, que constituye una mediación que restituye esos lazos comunitarios de los que habla Lavigne. Algo similar ocurre con la manera en que se construye la relación de Lucas con su padre, un hombre más cercano al entorno rural del Valle del Cauca, que la pone en contacto con la vida del campo y sus labores. Así mismo, la manera en que se construyen los personajes de los usuarios de La calle (tienen nombres repetidos, aspectos uniformes, formas de vida estandarizadas, pero con visos de violencia mecánica) contrasta con la calidez y riqueza de detalles de los personajes con los que Lucas comparte su existencia.

De acuerdo con Lavigne (2013), "Feminist cyberpunk thus emphasizes the importance of physical contact and the relation between body image and a unified sense of self” (p. 78). La combinación de los niveles narrativos que propone Salgado en su novela se inserta en esta línea de exploración, al proponer alternativamente la construcción de una subjetividad sólida a partir de su corporeidad en el relato realista, y una disolución de la identidad individual en la serialización de yoes en el nivel del relato marco. Así mismo, la novela de Salgado se presta a una lectura geopolítica, si se piensa que los usuarios de La calle parecen provenir del mundo anglosajón, esto es, del norte global (frío), mientras que los proveedores de vida orgánica provienen en su mayoría del sur global (caliente) y, en particular, de Suramérica, ratificando 
el cliché de la sexualización geopolítica de los cuerpos, pero a la vez invirtiendo la relación productores (del norte)/consumidores (del sur) de las industrias culturales contemporáneas. En este sentido, la novela de Salgado la acerca a los estudios sobre la perspectiva queer y la postcolonialidad, en la línea de autores como Murat Aydemir, que podría explorarse en una reflexión posterior sobre esta obra. Y aunque la novela de Andrea Salgado parece ubicarse todavía en los debates más tradicionales en torno al binomio homosexual/heterosexual, su alternancia entre el tono realista y las convenciones de género de la ciencia ficción le permite proponer complejos juegos metaficcionales que la acercan a otras formas de experimentación de la literatura queer contemporánea.

En su propuesta de narratología corpórea, Punday (2003) señala que la reflexión sobre el cuerpo aparece en la narrativa a partir de la distinción entre cuerpos y no-cuerpos, pero también subraya que en la literatura de género esta distinción aparece problematizada, desdibujando el límite entre las dos cosas (p. 58). La novela de Salgado nos enfrenta a una de las figuras contemporáneas a través de las que la ciencia ficción ha contribuido a ello: la experiencia virtual de cuerpos ajenos, la simulación de la experiencia corporal.

\section{El futuro de Ismael: entre Space Opera y Soap Opera}

La obra de Diana Catalina Hernández está emplazada en un contexto de sexualidades y géneros fluidos e inestables. El viaje de Ismael es una novela que tiene elementos que la vinculan con la ciencia ficción clásica y otros que la asocian con la literatura queer, por un lado, y por otro, al melodrama. La historia se ubica en un contexto apocalíptico: la tierra está a punto de ser destruida por una catástrofe solar que amenaza con extinguir a la humanidad. No obstante, se ha desarrollado una estrategia de evacuación, a través del diseño de naves y de esferas que envuelven las casas y las convierten en vehículos de escape. En el punto en que comienza la historia, la catástrofe solar es considerada por muchos una teoría conspirativa. Quienes la defienden y divulgan son grupos de personas que han decidido modificar sus cuerpos, combinándolos con el ADN de distintas especies de animales, o alterando los miembros y órganos de acuerdo a lógicas diversas. Estos grupos sostienen que hay un plan para excluirlos de los procesos de evacuación de la tierra, pues los cuerpos modificados son mal vistos, e incluso perseguidos, por el sistema social imperante (los detentores del poder en 
este universo no son explicitados). Dentro de los grupos de cuerpos modificados, reunidos bajo la denominación de Movimiento de los Cuerpos Transformados, hay facciones con distintos grados de radicalidad, siendo los más extremos los Índigos, una organización que cree en el uso de la fuerza y en las acciones violentas como parte de su campaña por acceder a las formas de evasión del planeta, lo que ha hecho que el movimiento en general sea considerado como peligroso e incluso ilegal.

En este contexto, la novela narra la historia de Ismael, un joven que termina inmiscuido con estos grupos a través de sus relaciones sentimentales con dos personajes: el primero es Nadhi, un ser de género fluido pero que se identifica, lingüísticamente, como femenino, y que ha modificado su cuerpo, incorporándose una serpiente entre sus piernas que funciona como apéndice sexual; el segundo, también de género fluido y con modificaciones en sus ojos y su piel que le dan aspecto de tigre, es Yune, uno de los líderes del movimiento en Brasil y a quien conoce cuando viaja a ese país. La historia de Ismael se desarrolla en lo que se convierte en un triángulo amoroso con la reaparición de Nadhi, en una historia que alcanza su clímax cuando la catástrofe solar efectivamente ocurre y los tres personajes logran, a pesar de su militancia en el Movimiento de los Cuerpos Transformados, abandonar la tierra en las esferas de evasión.

La novela plantea abiertamente la cuestión de la corporeidad y el género, de mano del Movimiento de los Cuerpos Transformados. El primer encuentro entre Nadhi e Ismael ocurre en un escenario académico, donde aquella presenta el movimiento a un grupo de estudiantes universitarios, describiéndolo como uno

[...] que congrega a colectivos de personas que se practican cambios en sus cuerpos para explorar su identidad. Por ejemplo, de vampiros a krist, de aborígenes renacidos a robot-bodies, pero también de hombres a mujeres o viceversa. En el caso de nuestros compañeros más transgresores, puede tratarse también de transformaciones para llegar al híbrido entre humano y cualquier otro animal o cosa (Hernández, 2017, p. 31).

Algo similar ocurre con Yune, su segunda pareja, a quien también conoce en el escenario de un discurso público, una especie de manifiesto de los cuerpos transformados, en tono aún más enfático:

Les voy a pedir que recuerden cómo muchos de estos cuerpos acabados de tocar son posibles únicamente gracias a una ardua lucha de liberación. Primero, aquellos que fueron rechazados por sus pintas en la piel, por esas agujas con las cuales, llenos de satisfacción, ellos se escribían. También las perforaciones en las orejas, las cejas, en los pezones y hasta en la boca. Quiero que recuerden las épocas oscuras en las cuales estos cuerpos eran marcados con dos letras 'f' y ' $m$ ', casillas, cárceles (p. 72). 
El discurso de Yune introduce además otra arista en las reflexiones de la novela sobre el sexo, el género y el cuerpo: el rol del lenguaje en la construcción de estas categorías, subrayado por Judith Butler y otras teóricas feministas y queer. Este cuestionamiento se expresa directamente en otros pasajes de la novela:

\begin{abstract}
“Hola, soy Ismael. ¿Cuál es tu pronombre?”. Ismael y todos los del movimiento hacían esta pregunta cuando no les resultaba clara la identidad de quien se encontraba al frente. Mi nombre es mi mantra. La identidad habita en cada letra que vibra en el aire. Mi pronombre. A favor del nombre. En lugar del nombre. Un nombre para él, un nombre para ella. Es mentira. En lugar de mi nombre, otro nombre. En lugar de mi nombre, un mantra asexuado, sin género. En lugar de mi nombre, este cuerpo que habla (Hernández, 2017, p. 85).
\end{abstract}

En este punto, la novela de Hernández permite demostrar que la relación entre lenguaje y corporalidad no se entiende en la narratología queer y corpórea como una mera relación de representación: la manera en que se designan los cuerpos y las identidades de género no es un asunto de palabras, sino que involucra una "corporeidad textual”, en el que las palabras resuenan con las experiencias sensoriales y sensuales de los cuerpos.

Así, en la novela de Hernández la dimensión discursiva se asocia con el deseo, en un aparente dualismo erótico: en la caracterización de Ismael se enfatiza el hecho de que es un ser incapaz de experimentar placer, víctima de una suerte de erotofobia (ese es el título de uno de los capítulos). Sin embargo, por otro lado, es definido como un "ninfómano de cerebros", al que "la inteligencia lo excitaba en exceso" (p. 118). De modo que Ismael no carece completamente de deseo, y su encuentro con Yune está asociado con ello:

A pesar de la insistente declaración de su poca sexualidad, Yune era un cuerpo dispuesto, una flor abierta a todo. Ismael podía explorar todas las formas de acariciar esa flor, todas estaban permitidas. $\mathrm{Su}$ sexo era un ojo. Otro ojo de tigre que parpadeaba con rapidez o lentitud. Era un ojo misterioso y hechicero, porque no revelaba el alma de nadie (p. 108).

Tanto en su relación con Nadhi como en la que sostiene con Yune, Ismael pasa de ser la contraparte que busca y desea al principio, a aquella que es buscada y deseada. $\mathrm{Su}$ incapacidad para el placer, una vez es rechazado y toma su camino, lo convierte en el objeto del deseo de sus parejas, ambas caracterizadas como seres atrayentes y vistosos. Paradójicamente, la novela se centra más en conflictos emocionales clásicos, acercándose más al melodrama (en una estructura convencional de soap opera) que 
al horizonte experimental de la ciencia ficción que, en este caso, termina como una space opera en la que una pareja de rebeldes es perseguida en planetas exóticos por su transgresión a un nuevo orden cósmico.

No obstante, la novela triunfa en su construcción de los personajes en tanto agentes corporeizados, pero cuyos cuerpos son maleables y se entregan a las transformaciones más radicales: en la última parte de la novela, por ejemplo, Nadhi se incorpora piel de rana y otras características del cuerpo de estos anfibios en su anatomía, así como Yune ha asumido rasgos felinos. Si los límites sexuales o genitales de los cuerpos han sido desdibujados desde un comienzo, el horizonte mismo de lo humano deja de ser la última frontera. Este tema es llevado aún más lejos por la obra de Luis Carlos Barragán.

\section{E1 Gusano: el andrógino queer y la frontera animal}

Dentro de la obra de Barragán, la novela que se inscribe más abiertamente en una perspectiva queer es Vagabunda Bogotá (2011). No obstante, se ha elegido para este análisis su novela El gusano (2018), en tanto su reflexión sobre el cuerpo en el marco de un relato de ciencia ficción apocalíptica puede interpretarse como una expansión en la teoría del género y la corporeidad.

La novela nos ubica en un momento en el que la humanidad se ve aquejada por una pandemia global que afecta todos los cuerpos, de manera que cualquier contacto físico entre las personas, si se da directamente de piel a piel, conduce a una fusión. De ahí que todo el mundo se ve obligado a envolverse en prendas que deben cubrir la mayor cantidad de piel, incluyendo sus rostros.

La historia está focalizada en César, narrador autodiegético que cuenta su primera y definitiva fusión, ocurrida cuando era un niño, con Sara, una niña siria:

Al principio sentí su piel cálida contra mi piel, pero luego comencé a sentir otras cosas. Mis manos comenzaron a hundirse en su epidermis. Mi cuello, de alguna forma, se abrió y casi por accidente mis vertebras tocaron sus vertebras. Sentí su corazón latiendo con fuerza dentro de mi pecho. Ella fue más adelante, como tomando impulso, y dando un paso a través de mi cuerpo. Por un instante sus órganos internos pasearon dentro de los míos y nuestras venas compartieron la sangre, las hormonas y todas las otras cosas salvajes que corren en nuestro interior. Nuestros cráneos se unieron como células en una mitosis en reversa con núcleos que intentaban definirse en un instante de furia, como "yo soy yo, y tú eres tú" con ojos que navegaban entre la materia gris y una nariz que avanzaba por el complejo óseo y la calidez de la boca húmeda, en completa oscuridad [...]. Ella salió caminando por mi espalda, saboreando mis vértebras, y yo me quedé quieto, sintiendo hasta la mierda de niña de sus intestinos y sus diminutos ovarios dentro de mí (Barragán, 2018, p. 13). 
Después de este encuentro, César mantiene el núcleo de su identidad, pero también se ve invadido por aspectos de Sara, entre rasgos físicos y memorias, que ahora son parte suya. Esta es una de las ideas más sutiles y sugerentes de la novela: la fusión corporal supone una fusión psicológica, donde no hay cabida a dualismos cartesianos. Los recuerdos y las emociones de Sara se encuentran, fragmentados y dispersos, en todo el cuerpo de César, que se ha convertido en "un accidente de transexualidad de 6 años" (p. 17).

De ahí en adelante, César se siente incompleto y añora el reencuentro con Sara, cuya identidad también está impregnada de la suya. Más tarde, en su adolescencia, César conoce a Francisco en una velada de runners: jóvenes que corren y se chocan para mezclarse parcialmente entre todos, hasta que ocurre una fusión generalizada, de manera que el cuerpo de uno de ellos ha quedado disperso entre los otros. El personaje desaparecido se llama Andrés Camilo, y ahora forma parte de una entidad colectiva de 16 muchachos, cada uno de los cuales preserva una parte de su identidad, por lo que empiezan a llamarlos los Andrés Camilos: "lo que habría respondido solo una parte de la psique de Andrés Camilo se complementaba con lo de otra persona. Una auténtica carnicería freudiana” (p. 37).

Otros fenómenos asociados con la fusión hacen que esta sea catalogada como una pandemia y que sea proscrita. Esto afecta las prácticas sexuales e induce a la sociedad hacia una "nueva edad media" de recatamiento y fanatismo:

Debido al accidente en el que una mujer terminó teniendo una lengua con prepucio después de fusionar su boca con los genitales del hombre al que le daba una mamada, el sexo en casi todas sus manifestaciones se había convertido en un acto deformante, aberrante, destructivo y, por supuesto, el crecimiento demográfico se había estancado en la mayor parte del mundo (p. 43).

Ya mayor, César se va a vivir a Bogotá, y termina trabajando como fotógrafo y reportero, gracias a que, en una de sus visitas a Timbío, registra una toma guerrillera que consiste en que los insurgentes se fusionan a la fuerza con la población. En el contexto de la novela, la guerrilla ha cambiado su causa ideológica: ya no es la toma del poder por la vía armada, sino que ahora consiste en el ideal de practicar la fusión y acabar definitivamente con las diferencias entre los seres humanos, con el egoísmo y el individualismo. Las imágenes y el testimonio que recoge César de este evento le permiten conseguir trabajo en los medios de comunicación, lo que le da la oportunidad de viajar por todo el mundo. Es justo en uno de estos viajes que logra reencontrarse con Sara. 
Mientras se narra la historia de estos dos personajes, la novela describe las distintas consecuencias de la fusión en la sociedad, que va derivando hacia el caos con el transcurso de la historia: los cuerpos se van fusionando en número creciente, sobre todo porque cada vez más personas deciden fusionarse voluntariamente, para alcanzar una nueva forma de existencia, aunque siguen siendo minoría, y las grandes mayorías consideran la fusión como una forma de monstruosidad que debe ser contenida o reducida. Aun así, conglomerados de muchas personas empiezan a transformarse en inmensos gusanos, identidades múltiples unificadas. Paralelamente, se han creado facciones fascistas anti-fusión que procuran mantener los cuerpos impolutos, pero esto es cada vez más difícil. Aunque las identidades individuales no desaparecen del todo, dicha fórmula tiene cada vez menos sentido.

Finalmente, la fusión definitiva entre Sara y César da lugar a una especie de andrógino místico de fuertes resonancias herméticas, un personaje que es el eje que estructurará el nuevo orden de una humanidad sin límites individuales.

La propuesta de Barragán en su novela va más allá del cuestionamiento de la relación entre cuerpo, género y sexualidad, aunque también la involucra. La fusión neutraliza todas las categorías, todas las diferencias, sin caer en la uniformidad. Los cuerpos metastásicos de los diversos monstruos hechos de criaturas fusionadas derivan en resonancias místicas y la fusión se hace casi una integración cósmica. En cierto sentido, la distopía pandémica deviene una utopía de la integración absoluta de los seres.

Y hay otro aspecto que hace aún más radical la propuesta narrativa de Barragán: las fusiones no se dan solo entre cuerpos humanos, pues es posible fusionarse con cualquier otro ser vivo, al menos del reino animal. En uno de los capítulos consagrados al nuevo rol revolucionario de las guerrillas, se narra la historia de Toño Rodríguez,

[...] un muchacho de 22 años, [que] se escudriñó de la guerrilla en la selva de San Vicente del Caguán a una cueva que los locales conocen como la cueva de las golondrinas. Sus amigos dicen que era un muchacho creativo, que él realmente quería un cambio para su país. Las fusiones accidentales le parecieron interesantes y decidió ir a la cueva por sí solo. [...] Durante horas, cientos de golondrinas fueron absorbidas por el cuerpo de Toño, hasta que la concentración de Toño/Golondrinas fue incontenible y el cuerpo de Toño se desintegró en Golondrinas (Barragán, 2018, p. 54).

Desde ese momento, a Toño se le conoció como “el pájaro", pues aprendió a controlar su capacidad para mantener la forma humana o disgregarse en cientos de aves cuando 
era capturado o perseguido, y lo propio hicieron muchos otros guerrilleros, fusionándose con distintos animales.

En este aspecto El gusano se aproxima a la novela de Diana Catalina Hernández, en tanto ambas hacen eco de lo señalado por Patricia McCormack (2009) acerca de las transformaciones contemporáneas de la corporeidad:

$[\ldots .$.$] there is no longer a category of human, or more precisely, the category of human was always$ the mythical zenith of an equal mythical zenith arboreal structure which systematized human subjectivity through religious, metaphysical and evolutionary discourses. [...] that which divides man from animal encompasses a far wider colonization of life through discourse (p. 135).

En la perspectiva de McCormack, el devenir-animal (concepto que la autora toma de Deleuze y Guattari) es una trayectoria queer del deseo que invita a llevar la transformación de los cuerpos aún más lejos:

Animal entities, more correctly non-human animals, in their almost infinite varieties, pose a far greater challenge to thought, be it through activism, philosophy or science. Closing the chasm between human and the animals is like closing the gap between discourse and non-discourse, between thought and the unthinkable but nonetheless necessary, and between our own relationships with our human selves (McCormack, 2009, p. 135).

En la novela de Luis Carlos Barragán, esta línea del recurso al hermetismo (a través del tema del andrógino) puede leerse como una regresión humanista y metafísica, sin que esto llegue a neutralizar su riqueza de ideas e imágenes. Haciendo eco de las ideas de McCormack, esta novela extiende las posibilidades de las narrativas queer hacia un plano de inmanencia donde la vida se despliega como pura potencia, y en el que los cuerpos (humanos, no humanos) no son más que puntos de tránsito. De acuerdo con la narratología corporal de Punday, la manera en que un texto aborda la corporalidad determina en gran parte la manera en que sus lectores se aproximan al mundo narrativo y a sus personajes, al tiempo que construye un nicho hermenéutico en el que distintas corporalidades se confrontan. En este proceso, todo texto formula un "cuerpo general" que atraviesa la narración, y determina sus concepciones del tiempo y el cambio (Punday, 2003, p. 85). Así, la narrativa realista tradicional concebía los cuerpos como la sede de identidades fijas y estables. La narrativa de ciencia ficción contemporánea, a la que pertenece El gusano (como también El viaje de Ismael), ofrece un nicho hermenéutico completamente distinto: la identidad se construye en un plano de multiplicidades donde el cuerpo mismo se diluye. 


\section{Conclusión}

En el marco de una tradición que apenas comienza a dibujarse (la de la ciencia ficción colombiana), las novelas de Quintana, Hernández y Barragán se desprenden de toda timidez a la hora de emplazarse en uno de los campos más experimentales de la literatura de ciencia ficción en el panorama contemporáneo: la redefinición radical de las formas narrativas ancladas en el posicionamiento unívoco de la sexualidad y la corporeidad. Dos de ellas tratan de llevar esta redefinición más allá del binario homosexual/heterosexual, e incluso del binario humano/no humano ( $E l$ gusano y $E l$ viaje de Ismael), mostrándose más radicales en su experimentación en el ámbito de los cuerpos representados.

La novela de Salgado, por su parte, ofrece una aproximación ligeramente más conservadora en este sentido, al mantenerse en los límites de estos binarismos, pero al mismo tiempo ofrece una reconsideración más versátil y arriesgada en el nivel de la enunciación narrativa y los mecanismos de la mediación corporal de la narración, a través del juego con estrategias metaficcionales que evocan el rol de los cuerpos, la experiencia vicarial y el deseo en el marco de las tecnologías contemporáneas. Con todo, las tres novelas contribuyen a la consolidación de un género que siempre se ha proyectado hacia el futuro, y que ha convertido al cuerpo en el dominio más radical de sus extrapolaciones.

\section{Referencias bibliográficas}

Albert, J. y Fludernik, M. (2010). Postclassical Narratology. Approaches and Analyses. Columbus: The Ohio State University Press.

Barragán, L. C. (2018). El gusano. Bogotá: Ediciones Vestigio.

Butler, J. (2007). El género en disputa. El feminismo y la subversión de la identidad. Barcelona: Paidós.

Carroll, R. (2012). Rereading Heterosexuality. Feminism, Queer Theory and Contemporary Fiction. Edinburgh: Edinburgh University Press. Recuperado de https://ibrary.oapen.org/hand$\underline{\text { le/20.500.12657/30783 }}$ [10.11.20201].

Hernández, D. C. (2017). El futuro de Ismael. Bogotá: Ediciones B.

Lavigne, C. (2013). Cyberpunk Women, Feminism and Science Fiction. A Critical Study. Jefferson, North Carolina, and London: McFarland \& Company.

McCormack, P. (2009). Unnatural Alliances. En C. Nigianni y M. Storr (Eds.). Deleuze and Queer Theory (pp. 134-149). Edimburg: Edimburg University Press. 
Pearson, W., Hollinger, V.y Gordon, J. (2008). Queer Universes. Sexualities and Science Fiction. Liverpool: Liverpool University Press.

Punday, D. (2003). Narrative Bodies. Toward a Corporeal Narratology. New York: Palgrave MacMillan. Salgado, A. (2017). La lesbiana, el oso y el ponqué. Bogotá: Penguin Random House.

Suvin, D. (1984). Metamorfosis de la ciencia ficción. Sobre la poética y la historia de un género literario. México: Fondo de Cultura Económica.

Warhol, R., y Lanser, S. S. (2015). Narrative Theory Unbound. Queer and Feminist Interventions. Columbus: The Ohio State University Press. 